\title{
An Overview of Submersible Research and Development in China
}

\author{
Weicheng Cui ${ }^{1}$
}

Received: 7 May 2018 / Accepted: 11 July 2018 / Published online: 8 January 2019

(C) The Author(s) 2019, corrected publication 2019

\begin{abstract}
Given the recent success in the development of several submersibles in China, people's interest in the history of submersible development is increasing. This paper presents the history of submersible development in China, which can be briefly divided into three periods. The first one is the early period of hardship (1971-2000). Many prototype submersibles of HOVs, ROVs, and AUVs were developed at this time, but the main achievement was the establishment of special research organizations and the training of research and development personnel. The second period can be regarded as the quick development period (20012015). All currently used submersibles were developed during this period. The most remarkable achievement was the successful development of $7000 \mathrm{~m}$-deep manned submersible "Jiaolong." The third period aims to develop $11000 \mathrm{~m}$ submersibles for challenging the full ocean depth (2016-2020). In this period, two unmanned submersibles and two manned submersibles will be the significant indicators of achievement. If this 5 -year plan can be successfully completed, China can play a significant role in the investigation of the deepest part of the oceans, namely, the hadal trenches $(6500-11000 \mathrm{~m})$.
\end{abstract}

Keywords Hadal trenches - Submersibles · Deep tow system · Lander · Glider - Autonomous and remotely operated vehicle $(\mathrm{ARV}) \cdot$ Human-occupied vehicle $(\mathrm{HOV}) \cdot$ Full ocean depth $(\mathrm{FOD})$

\section{Introduction}

Conflict among population, resources, and the environment in the twenty-first century has made the ocean a strategic space and resource treasure of human society to realize sustainable development. To study the ocean environment and exploit ocean resources, a fundamental understanding of complex and interwoven ocean processes across a broad range of spatial and temporal observational scales is required. Various research fleet and equipment are necessary to support increasingly complex, multidisciplinary, multi-investigator research projects, including those in support of autonomous technologies, ocean observing systems, process studies, remote sensing, and

This work was supported by the State Key Program of National Natural Science of China "Structural Reliability Analysis on the Spherical Hull of Deep Sea MSs" (Grant No. 51439004) and the Scientific Innovation Program Project of "Key technology research and experimental validation of deep MS" by the Shanghai Committee of Science and Technology (Grant No. 15DZ1207000).

Weicheng Cui wccui@ shou.edu.cn

1 Shanghai Engineering Research Center of Hadal Science and Technology, Shanghai Ocean University, Shanghai 201306, China modeling (CENORF 2009). Various underwater submersibles are the main working force for the research fleet. A submersible is a small vehicle designed to operate underwater. The term submersible is often used to differentiate from other underwater vehicles known as submarines; a submarine is a fully autonomous craft that can renew its own power and breathe air, whereas a submersible is usually supported by a surface vessel, platform, shore team, or large submarine. Submersibles can be divided into human-occupied vehicles (HOVs), remotely operated vehicles (ROVs), autonomous underwater vehicles (AUVs), hybrid ROV and AUV (HROV or ARV), and gliders. An HOV also known as a manned submersible (MS) is a type of submersible that can carry scientists, engineers, various electronic devices, and special equipment to arrive at various complex deep sea environments quickly and accurately. This vehicle can conduct efficient exploration, scientific investigation, and other deep sea operations. It is an important technical means to understand ocean phenomena and exploit ocean resources. A typical MS consists of four major components: a pressure hull, propellers (thrusters), buoyant materials, and observational and sampling instruments. Currently, the four types of different HOVs are MS, deep submergence rescue vehicle (DSRV), atmospheric diving suit (ADS), and rescue bell. An ROV is a tethered underwater robot that allows the vehicle's operator to remain in a comfortable environment while the 
ROV works in a hazardous environment below. The total ROV system comprises the vehicle, which is connected to the control van and operates on the surface by a tether or umbilical; a group of cables that carry electrical power, video, and data signals back and forth between the operator and vehicle; a handling system to control cable dynamics; a launch system; and associated power supplies. High power applications often use hydraulics in addition to electrical cabling. In many cases, the umbilical includes additional strength members to allow recovery of heavy devices or wreckage. The most commonly known unmanned underwater vehicle is the autonomous underwater vehicle (AUV). AUVs can be used for underwater survey missions such as detecting and mapping submerged wrecks, rocks, and obstructions that can be a hazard to navigate for commercial and recreational vessels. An AUV conducts its survey mission without operator intervention. When a mission is complete, the AUV will return to a pre-programmed location where the data can be downloaded and processed. Underwater gliders are autonomous vehicles that profile vertically by controlling buoyancy and move horizontally on wings (Rudnick 2015). A division of various submersibles is given in Fig. 1. The uses of these vehicles include offshore petroleum, telephone cable maintenance, science, surveying, salvage, and military functions. Recent overview papers include HOV (Kohnen 2009; Moorhouse 2015), ROV (Christ and Wernli 2014; Teague et al. 2018), AUV (Wynn et al. 2014), HROV (Bowen et al. 2004) or ARV (Deng et al. 2014), glider (Rudnick 2015), deep tow system (DTS) (Marsset et al. 2010), lander (Tenberg et al. 1995), and drifters and floats (Richardson and John 2001).

However, in all these review papers, little information was given about the submersible development in China due to a lack of publications in early times. Furthermore, only two review papers that specifically focused on Chinese activities have been found with partial information, and they are now out of date (Pang et al. 1999; Zhu 2001). Therefore, the present author conducted a comprehensive survey of the development history and current status of various submersibles in China. This work may be useful for newcomers in China or for the international community.

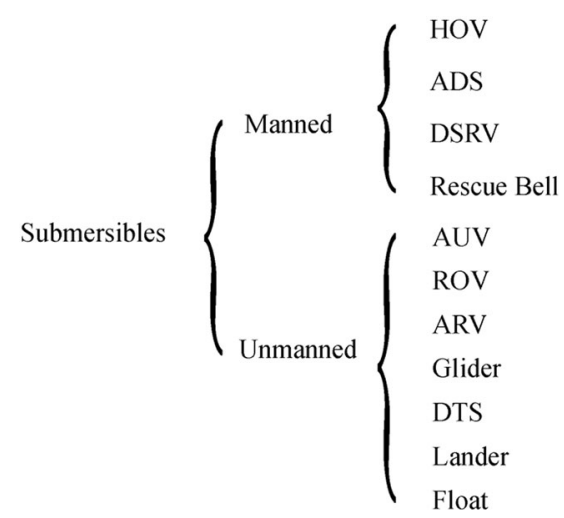

Fig. 1 Division of various submersibles

\section{Early Period of Hardship (1971-2000)}

\subsection{Human-Occupied Vehicle (HOV)}

The earliest submersible developed in China was a DSRV named "7103," which indicated that the project started in March 1971. This submersible was jointly developed by Shanghai Jiao Tong University (SJTU), China Ship Development and Design Center (CSDDC), and Wuchang Shipbuilding Industry Co., Ltd. The submersible was of $15 \mathrm{~m}$ length and 35 tons displacement. The maximum design depth was $600 \mathrm{~m}$, but the actual depth reached in sea trials was only $300 \mathrm{~m}$. It was put into service by the Chinese navy in 1987.

In China, governmental funding was run in a 5-year basis, with 1956-1960 as the first 5-year plan. In the sixth 5-year plan period from 1981 to 1985, China Ship Scientific Research Center (CSSRC) developed the first ADS named "QSZ-I" for the Chinese navy. In the next 5 years from 1986 to 1990, CSSRC continued the development of another improved ADS named "QSZ-II." Both of them are of $300 \mathrm{~m}$ diving depth.

From 1991 to 1995, Harbin Engineering University (HEU) in cooperation with CSDDC developed a torpedo salvage vehicle "Yuying." It was a MS of $200 \mathrm{~m}$ diving depth. From 1996 to 2001, CSSRC developed a rescue bell of $200 \mathrm{~m}$ depth.

\subsection{Remotely Operated Vehicle (ROV)}

In the late 1970s and early 1980s, Shenyang Institute of Automation (SIA) of the Chinese Academy of Sciences (CAS) in cooperation with SJTU started to develop the first ROV "HR-01" in China. This project was completed in the sixth 5-year period. It was an ROV of $200 \mathrm{~m}$ diving depth. In the next 5-year period from 1986 to 1990 , SJTU continued the development of ROV "HR-02" while SIA developed "Recon IV" ROV; both vehicles are of $200 \mathrm{~m}$ diving depth. Subsequently, SIA focused on the development of AUV, whereas SJTU continued the development of ROV of HR series such as HR-03 and HR-04. All these vehicles can be regarded as the prototypes of ROVs, and they have not been put into service.

In the 8th 5-year plan from 1991 to 1995, CSSRC finished the development of a 600-m ROV "8A4." It successfully completed sea trials but was not put into service.

\subsection{Autonomous Underwater Vehicle (AUV)}

The first AUV developed in China was called "Explorer," and its maximum diving depth was $1000 \mathrm{~m}$. It was jointly developed by SIA, CSSRC, and Institute of Acoustics (IOA) of the CAS from 1991 to 1994. From 1992 to 1997, the AUV team in cooperation with Russia developed the first 6000-m AUV 
named "CR-01" under the support of the Ministry of Science and Technology (MOST); from 1998 to 2002, an improved 6000-m AUV named "CR-02" was further developed. Both "CR-01" and "CR-02" finished sea trials with a maximum diving depth of $5280 \mathrm{~m}$, but these two submersibles have never been put into service due to various reasons.

Similarly, HEU started to develop AUVs for military use. They developed the "Zhishui I" prototype in 1992, "Zhishui II" in 1995, and "Zhishui III" in 2000.

\subsection{Early Four Main Research Organizations}

Although the development of various submersibles in China started as early as the 1970 s, progress was initially slow. Almost all the submersibles developed were prototypes due to various reasons, and they did not play any significant role in deep sea studies. However, four organizations formed a special division for submersible development. These organizations are CSSRC, which mainly focused on HOV under the leadership of Xu Qinan (1936-present), now an academician of Chinese Academy of Engineering (CAE); SJTU is strong in ROV under the leadership of Zhu Jimao (1936-present); SIA is dominant in scientific AUV under the leadership of Jiang Xinsong (1931-1997), a former academician of CAE; and
HEU is mainly for military AUV development under the leadership of Xu Yuru (1942-2012), a former academician of CAE. From 1996 to 2000, SJTU developed the first 6000-m DTS named "SJTU-ST6000" in China. Figure 2 shows a list of submersibles developed in this first period, during which few publications were made internationally (Pang et al. 1999; Zhu 2001). Therefore, little influence was caused in the international community about submersible development in China.

\section{Quick Development Period (2001-2015)}

\subsection{Urgent Need of Various Submersibles by China Ocean Mineral Resources R\&D Association (COMRA)}

In the late 1990s, the International Seabed Authority (ISA) started the draft of regulations on prospecting and exploration for polymetallic sulphides and cobalt-rich ferromanganese crusts. COMRA is the Chinese representative in ISA, and they urgently needed various submersibles to explore international oceans. On the basis of the experience of various submersible developments in the early period, COMRA sponsored SJTU in 2001 to develop a workable ROV of $3500 \mathrm{~m}$ depth named "Hailong." The first one was lost in sea trials due to cable
Fig. 2 Representative prototype submersibles developed in China from 1971 to 2000

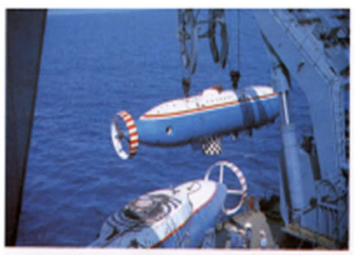

7103DSRV

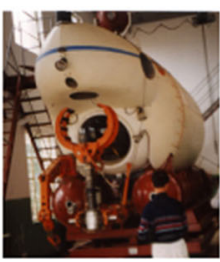

Yuying

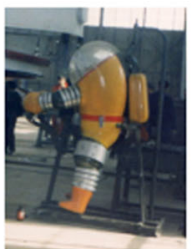

QSZ-I ADS

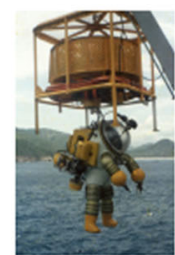

QSZ-II ADS

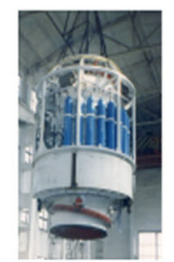

Rescue Bell

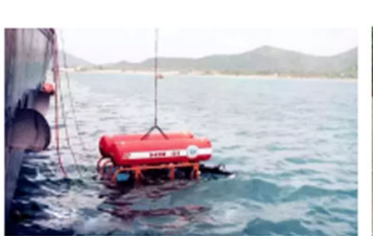

HR-01

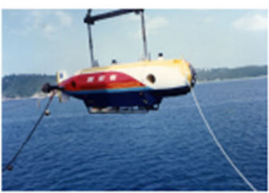

Explorer

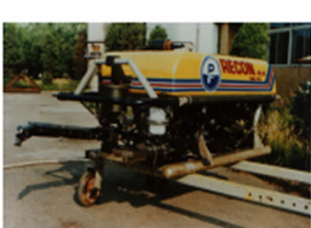

Recon IV

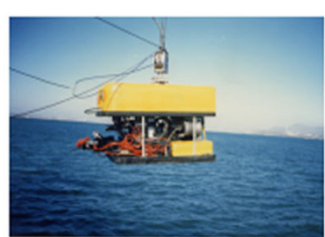

8A4 ROV

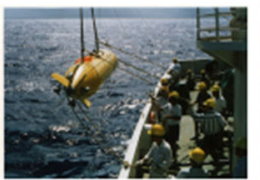

CR-01

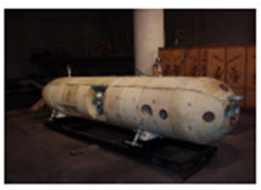

CR-02

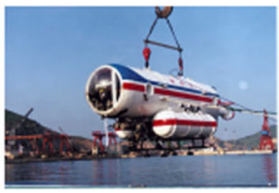

Zhishui II(7B8) 
breakage, and the team continued to develop a second one. "Hailong II" successfully finished sea trials and was put into service in 2009. At the same time, COMRA successfully persuaded the MOST to fund the project to develop a deep MS of $7000 \mathrm{~m}$ depth. This project was coordinated by COMRA as the final user, and it contained four subprojects: submersible development, the development of a launch and recovery system together with mothership upgrade, the selection and training of pilots for sea trials and future application, and the establishment of future management center for submersible operation. CSSRC, SIA, and IOA are the leader institutes for submersible development, whereas CSDDC is in charge of the development of launch and recovery system together with mothership upgrade. COMRA is responsible for the selection of pilots for sea trials and the establishment of future management centers for submersible operation. In this project, many papers have been published (e.g., Guo et al. 2006; Yu et al. 2007; Pan et al. 2010, 2012; Pan and Cui 2012, 2013; Cui et al. 2013; Wang et al. 2014; Wang et al. 2015a, b; Wang and Cui 2015; Liu et al. 2015; Gao et al. 2016).

From 2011 to 2013, SIA was tasked by COMRA to develop another usable 6000-m class AUV, and this vehicle was successfully constructed. It was named "Qianlong-1" (Wu et al. 2014). In the same period, HEU continued the development of "Zhishui IV" and "Zhishui V" AUVs for the Chinese navy, and several papers about the vehicles' progress have been published (e.g. Zhang and Chu 2011; Zhang et al. 2011).

Figure 3 shows all these submersibles that have been successfully developed and put into service. Notably, the success of "Jiaolong" has remarkably influenced China's decision on the development of various submersibles in the following years. Cui (2013) has presented in detail the development process and its technical achievement of the "Jiaolong" submersible.

\subsection{Development of 4500-m Class Domestically Made Submersibles}

In the 11th 5-year period (2006-2010), a substantial number of people did not believe that the "Jiaolong" submersible could be successfully developed. Thus, in the 12th 5-year plan, emphasis was placed on $4500 \mathrm{~m}$, which is a practical required depth. One submersible in each category of AUV, ROV, and HOV was sponsored by MOST. The main emphasis of MOST is that more than $90 \%$ equipment must be built in China due to the technical blockage previously met in the development of "Jiaolong." One of each ROV, HOV, and AUV was initiated in 2008, 2009, and 2010, respectively, by MOST. The ROV ("Haima4500"), HOV ("Shen Hai Yong Shi [Deep Sea Warrior]," and AUV ("Qianlong II") finished sea trials in 2014, 2017, and 2016, respectively (Fig. 4). Several papers have been published concerning the development of Haima 4500 ROV (Fan et al. 2012; Lian et al. 2015; Tao and Chen 2016; Ping et al. 2017).

\subsection{Development of Hybrid Submersibles, Gliders, Landers, DTSs, and Deep Floats}

Given the increased support from MOST for various submersibles, an increasing number of research organizations have started to conduct various studies and developments for different submersibles. When WHOI started the development of the hybrid concept of AUV and ROV (Bowen et al. 2004), some researchers from SJTU, CSSRC, and SIA began to explore this concept as well. In 2006, they jointly persuaded the Ministry of Industry and Information Technology (MIIT) to sponsor a project to develop a similar unmanned submersible named "Nereus." This concept was first proposed by McFarlane in 1990 (McFarlane 1990) and implemented in Japan as a $7000 \mathrm{~m}$ class expendable optical fiber cable ROV (UROV7K) (Nakajoh et al. 1998). The main idea of HROV is that it will operate in two different modes. For broad area survey, the vehicle will operate in fully autonomous, untethered mode and map the seafloor with sonars and cameras. After targets of interest have been found, the vehicle will be converted at sea to an ROV mode that will permit close-up imaging and sampling. The ROV mode will include an add-on capability for cameras, lights, a manipulator, and sampling gear. In the ROV mode, a lightweight fiber optic cable to the surface will permit the high bandwidth feedback to the surface
Fig. 3 Photos of three submersibles, namely, "Hailong," "Qianlong I," and "Jiaolong"

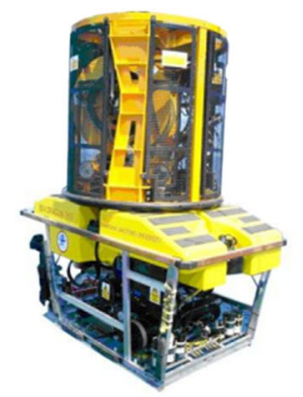

Hailong II

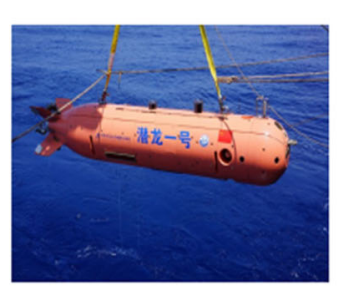

QianlogI

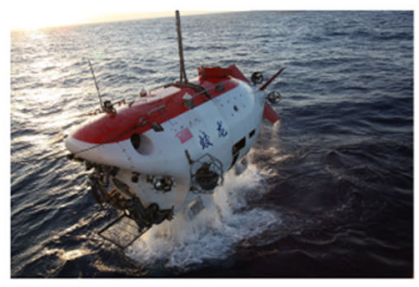

Jiaolong 
Fig. 4 Three 4500-m class submersibles

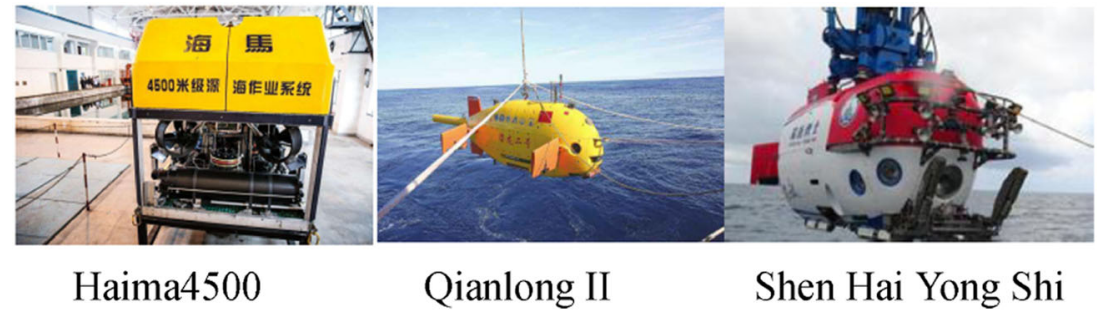

to permit high-quality teleoperation (Bowen et al. 2004). In China, this vehicle was called autonomous and remotely operated vehicle (ARV) (e.g. Li et al. 2011; Feng et al. 2011; Deng et al. 2014). Both CSSRC and SIA retreated from the project because of inadequate funding and other reasons, but SJTU continued the development. Prototype development was completed after a lake test in 2012, and the ARV was named "Long Huang" (Deng and Ge 2012; Wang et al. $2013 \mathrm{a}, \mathrm{b})$. This submersible has now been updated and renamed to "Hailong11000." It has just finished 4000-m depth sea trials in April 2018, and it will continue to undergo sea trials next year.

SIA received additional support from MOST and started the development of a 100-m depth ARV named "Arctic" because its main mission was working under ice (Li et al. 2011). Simultaneously, CSSRC started the development of $300 \mathrm{~m}$ class "Haizheng" (Xu et al. 2010). The first prototype was completed in 2012, and CSSRC received an order from Shanghai Maritime University (SMU) to develop another one. It was initially named "Haizheng II" but later changed to "Haishi (Maritime)" (Deng et al. 2014).

In 2016, Shanghai Ocean University (SHOU) developed the "Rainbowfish" ARV (Cui et al. 2017) while SIA developed "Hadal" ARV; both vehicles were for $11000 \mathrm{~m}$ depth. "Hadal" ARV successfully reached the Challenger Deep in 2016, but it was lost in an operation during a cruise the following year. "Rainbowfish" ARV underwent second sea trials in the cruise from December 2016 to February 2017, but the maximum diving depth reached was only $6300 \mathrm{~m}$ due to various problems.

Since 2003, SIA started to develop the first glider in China. The prototype completed lake trials in 2006, and SIA received funding support to develop the "Haiyi" series of gliders in 2007. In 2009, 300-m depth sea trials were completed (Yu et al. 2011). Thereafter, they developed gliders for deeper depths, and the glider that could reach the deepest parts was "Haiyi7000" (Chen et al. 2015a, b, c). She successfully reached $6329 \mathrm{~m}$ in the Marina trench in March 2017, and that depth remains the current maximum depth a glider has ever reached. In Tianjin University (TU), another group under the leadership of Professor Shuxin Wang started to develop "Hai Yan" series in 2006; they have also achieved great success (Wang et al. 2007, 2009; Liu et al. 2014a, b; Lei et al. 2016a, b; Ma et al. 2016; Wang et al. 2017; Wu et al. 2017).
The maximum diving depth reported is $1500 \mathrm{~m}$, and they have received numerous orders for massive production. CSSRC started the development of gliders in 2012, and their second glider "Haixiang" reached a depth of $503 \mathrm{~m}$ in 2016 (Chen et al. 2015a, b, c). In addition to these organizations, many other groups have expressed interest in developing various specific-purpose gliders. They include Northwestern Polytechnical University (Tian et al. 2012), Zhejiang University (Fan and Woolsey 2013; Fan et al. 2014; Yang et al. 2014), Hangzhou Dianzi University (Chen et al. 2015a, b, c), SJTU (Yang and Ma 2010; Cao et al. 2015), Ocean University of China (OUC) (Fan et al. 2016), and National Ocean Technology Center (NOTC) (Qi et al. 2013).

DTS is a comprehensive observation instrument system towing under a ship for deep sea geology and geophysics. It is usually equipped with a precision navigation and positioning system, which consists of a side scan sonar, narrow beam precision echo sounder, profiler, magnetometer, stereo camera, continuous temperature measuring device, substrate or biological sampler, and other geological and geophysical observation instruments (Marsset et al. 2010). As previously mentioned, SJTU developed the first 6000-m SJTU-ST6000 in 1999. Under the support of MOST, the IOA developed another two 6000-m DTSs in the period of 2001 to 2015.

"Lander" is a general term for any autonomous, unmanned oceanographic research vehicle that free falls to the sea floor unattached to any cable and then operates independently on the sea floor. At the end of deployment, ballast weights are released either by a pre-programmed timing device or on an acoustic command transmitted from the surface. The lander then floats back up to the surface by virtue of its positive buoyancy. Other terms that have been used for such devices are "free-fall vehicle" and "pop-up vehicle" (Tenberg et al. 1995). In the period of 2011 to 2013 , SIA developed the first lander of $3000 \mathrm{~m}$ depth named "Cold sweep." They then developed two other FOD landers named "Tianya" and "Haijiao" from 2013 to 2016. In the same period, SHOU developed three different "Rainbowfish" series FOD landers. All these five landers have successfully reached the Challenger Deep in 2016.

NOTC has conducted research and development of drifters and floats since 1999; in 2003, they successfully finished 
2000-m depth sea trials of class float "China Ocean Profiling Explorer (COPEX)" (Yu 2003; Yu et al. 2005). In 2005, No. 710 Institute (710 Institute) of China Shipbuilding Industry Cooperation (CSIC) developed another 2000-m depth class float "HM2000" (Lu et al. 2016). Currently, OUC, SJTU, and SHOU are starting the development of 4500-m depth class floats.

\section{Challenge of the FOD Period (2016-2020)}

\subsection{FOD Submersibles Under Development in China}

After the success of the "Jiaolong" deep MS in 2012, many people predicted that the focus in the 13th 5-year period will be FOD. They then started the preparation for the proposal to MOST for developing FOD submersibles. CAS set up a specific research project in 2013 to develop FOD landers and ARV. The "Hadal" ARV and two landers "Tianya" and "Haijiao" are the result of this project. The present author was invited by SHOU to establish a Hadal Science and Technology Research Center (HAST) to specifically focus on hadal zones. To speed up development, HAST introduced a new funding mode called "governmental support+private investment" and worked in close cooperation with Shanghai Rainbowfish Ocean Technology Co. Ltd. (RFOT). They intended to develop a comprehensive investigation system for the survey of hadal trenches (Cui et al. 2014; Cui 2015; Cui and Wu 2018). The system consists of three FOD landers, one FOD ARV, one FOD HOV, and a 4800-ton displacement mothership. The construction of the first phase of this comprehensive investigation system has been completed. Figure 5 shows an image of this comprehensive investigation system, which includes three "Rainbowfish" series landers, one "Rainbowfish" ARV, and the mothership "Zhang Jian."

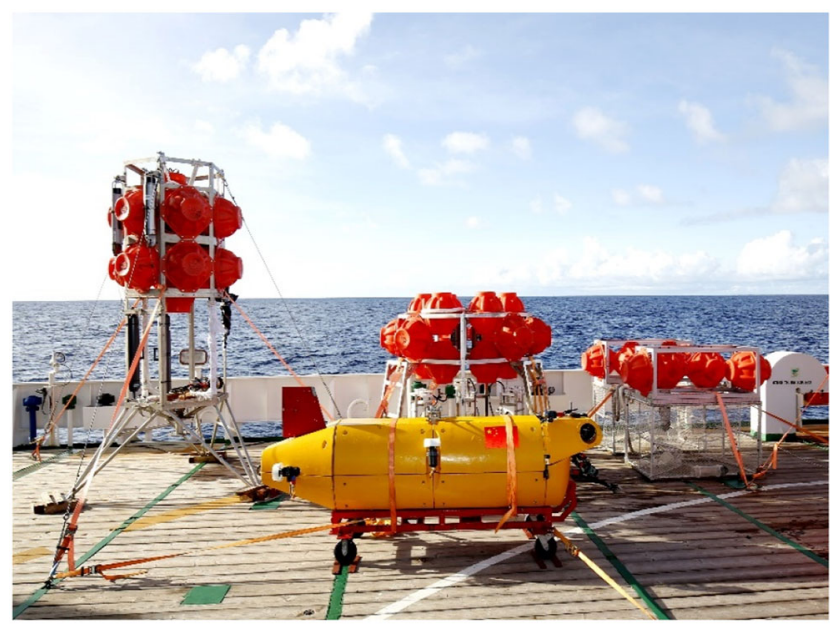

Fig. 5 ARV (front) and three landers (behind) on the mothership "Zhang Jian"
In 2016, their speculations were confirmed (Cyranoski 2016; Qian et al. 2016). Aiming at the important national demands in exploring deep oceans, exploiting deep ocean resources, and safeguarding ocean rights, MOST focused their funding support in the two main lines of deep sea science and technology. One is to develop 11000 -m-deep sea technology and become a country of sea power. The second is to improve the basic research level and original innovation ability of deep sea technology; form equipment with 1000-7000-m-level deep sea carrying and detecting, pedigree, localization, and supporting ability; and promote the development of deep sea technology and equipment industry. In this 13th 5-year period, MOST sponsored the development of two FOD ARVs and one HOV. After competition, SJTU and SIA will be the leading organizations responsible for developing one of the two ARVs, whereas CSSRC is the leading organization responsible for developing the FOD HOV. Although HAST did not win support from MOST, they continued the development of FOD HOV "Rainbowfish" with the support from various local governments and private investment to RFOT. Since 2018, RFOT has also invested in developing another $6000-\mathrm{m} \mathrm{HOV}$ to form a fleet that aims to provide better services to ocean scientists with capability of full ocean areas and FOD.

In addition to supporting these FOD submersibles, MOST has also funded other submersibles to complete the spectrum of submersibles. Scientists in China have defined five depth levels for the spectrum, namely, 500, 2000, 4500, 7000, and $11000 \mathrm{~m}$ (Qian et al. 2016).

\subsection{Main Technical Challenges for the Development of FOD Submersibles}

The most challenging aspect of the development of various submersibles is the development of the FOD HOV because almost all the technology challenges encountered in the development of unmanned submersibles are covered by the HOV. Unmanned submersibles plus manned cabins are approximately equal to HOV. Both landers and ARV can be regarded as the test platforms for the development of the FOD HOV (Cui et al. 2014). The key technical issues solved in the development of ARV have been described in Cui et al. (2017).

The key technical issues to be solved for the development of the FOD HOV and their current progresses in China are described briefly in this section. The specific technical challenges for ROV and AUV or multi-AUVs can be found in Christ and Wernli (2014) and Vedachalam et al. (2018), respectively.

The most challenging issue is related to design, that is, how global optimum performance can be achieved. The design of the FOD HOV is a multidisciplinary issue that involves the compromise or optimization of many objectives and constraints. Thus, it is a multidisciplinary design optimization (MDO) issue. Two problems need to be addressed in this aspect. One is how to build the MDO mathematical model, 
Table 1 HOVs developed in China

\begin{tabular}{|c|c|c|c|c|c|c|}
\hline Name & Design depth $/ \mathrm{m}$ & Development period & $\begin{array}{l}\text { Chief organization for } \\
\text { the development }\end{array}$ & Sponsor & User & Other important information \\
\hline 7103 DSRV & 600 & $1971-1987$ & SJTU & Navy & Navy & Maximum sea trial depth $300 \mathrm{~m}$ \\
\hline QSZ-I ADS- & 300 & $1981-1985$ & CSSRC & Navy & Navy & \\
\hline QSZ-II ADS & 300 & $1986-1990$ & CSSRC & Navy & Navy & \\
\hline Yuying Torpedo salvage & 200 & $1991-1995$ & HEU & Navy & KSERTC & \\
\hline Rescue Bell & 200 & $1996-2001$ & CSSRC & Navy & Navy & \\
\hline Mobile Rescue Bell & 200 & 2003-2005 & CSSRC & Navy & Navy & \\
\hline Jiaolong & 7000 & 2002-2013 & CSSRC & MOST & NDSC & \\
\hline Shen Hai Yong Shi & 4500 & 2009-2017 & CSSRC & MOST & IDSE & \\
\hline QSZ-III ADS & 500 & $2011-2015$ & CSSRC & MOST & CNOOC & \\
\hline Rainbowfish & 11000 & $2013-2021$ & SHOU & SHOU/RFOT & RFOT & \\
\hline- & 11000 & 2016-2021 & CSSRC & MOST & IDSE & \\
\hline
\end{tabular}

and the other is how to efficiently and accurately solve the mathematical problem. In the design of the "Jiaolong" deep MS, Cui and his group started to explore the possibility of applying MDO theory to design deep MSs, and many papers have been published in this aspect (e.g., Gou and Cui 2010; Zhao and Cui 2011; Zhao et al. 2015; Pan and Cui 2014). Moreover, a book was recently published about this concern (Pan and Cui 2017).

A comprehensive optimization design of the hydrodynamic layout for the FOD HOV is also required to achieve a high descent/ascent rate. To address this issue, the traditional approach of numerical computation with model tests is still applicable (Li et al. 2013). Jiang and Cui (2015) reported the optimization of the "Rainbowfish" HOV.
Furthermore, ergonomic interior design of a manned cabin must be implemented. The manned capsule is the working and living area for pilots and scientists. Given that the cabin must withstand extremely high FOD pressure and an industrial limitation exists for manufacturing large and thick manned cabins, the internal diameter of the manned cabin is only $2.1 \mathrm{~m}$ for "Rainbowfish" FOD HOV. This value is already the largest for existing three-person manned cabins for deep MSs. The diameter of the manned cabin for another FOD HOV sponsored by MOST is $1.8 \mathrm{~m}$. Maximizing the cabin design advantages of existing MSs and improving the comfort of crews within the small and closed environment is a critical issue. To date, no toilet has been equipped in any manned cabin, which is a main

Table 2 ROVs developed in China

\begin{tabular}{llllll}
\hline Name & Design depth/m & Development period & $\begin{array}{l}\text { Chief organization } \\
\text { for the development }\end{array}$ & Sponsor & User \\
\hline HR-01 & 200 & $1981-1985$ & SIA & MOST & SIA \\
HR-02 & 200 & $1986-1990$ & SJTU & - & SJTU \\
HR-03 & - & $1991-1995$ & SJTU & - & SJTU \\
HR-04 & - & $1996-2000$ & SJTU & - & SJTU \\
RECON IV & 200 & $1986-1990$ & SIA & - & SIA \\
8A4 & 600 & $1991-1995$ & CSSRC & MOST & CSSRC \\
Hailong I & 3500 & $2001-2005$ & SJTU & COMRA & - \\
Hailong II & 3500 & $2005-2009$ & SJTU & COMRA & COMRA \\
Hailong III & 6000 & $2016-2018$ & SJTU & COMRA & COMRA \\
Haima4500 & 4500 & $2008-2014$ & SJTU & MOST & Guangzhou Marine \\
Haima500 & 500 & $2010-2014$ & SJTU & SOA & SJTU the sea trial in 2003 \\
Haixiang1500 & 1500 & $2012-2015$ & SJTU & MOST & CNOOC \\
AUTO2000 & 2000 & $2015-2018$ & SJTU & MOST & AVI \\
Discovery & 6000 & $2013-2017$ & SIA & CAS & IDSE \\
- & 11000 & $2017-2025$ & SJTU & MOST & NDSC \\
\hline
\end{tabular}


Table 3 AUVs developed in China

\begin{tabular}{|c|c|c|c|c|c|c|}
\hline Name & Design depth/m & Development period & $\begin{array}{l}\text { Chief organization } \\
\text { for the development }\end{array}$ & Sponsor & User & Other important information \\
\hline Explorer & 1000 & 1991-1994 & SIA & MOST & SIA & \\
\hline CR-01 & 6000 & 1992-1997 & SIA & MOST & SIA & \\
\hline CR-02 & 6000 & 1998-2002 & SIA & MOST & SIA & \\
\hline Zhishui I & 100 & 1990-1992 & HEU & Navy & HEU & \\
\hline Zhishui II(7B8) & 100 & 1991-1995 & HEU & Navy & HEU & \\
\hline Zhishui III & 300 & $1996-2000$ & HEU & Navy & HEU & \\
\hline Zhishui IV & 300 & 2001-2005 & $\mathrm{HEU}$ & Navy & $\mathrm{HEU}$ & \\
\hline Zhishui V & 1000 & 2006-2010 & HEU & Navy & HEU & No deep sea trials arranged \\
\hline Chensha & 2000 & 2011-2015 & HEU & MIIT & CNOOC & \\
\hline Qianlong I & 6000 & $2011-2013$ & SIA & COMRA & NDSC & \\
\hline Qianlong II & 4500 & 2011-2016 & SIA & MOST & NDSC & \\
\hline Qianlong III & 4500 & 2015-2018 & SIA & MOST & NDSC & \\
\hline
\end{tabular}

Table 4 HROVs or ARVs developed in China

\begin{tabular}{|c|c|c|c|c|c|c|}
\hline Name & Design depth/m & Development period & $\begin{array}{l}\text { Chief organization } \\
\text { for the development }\end{array}$ & Sponsor & User & Other important information \\
\hline Hailong11000 & 11000 & $2006-$ & SJTU & MIIT & SJTU & 4000-m sea trials completed in April 2017 \\
\hline Arctic & 300 & $2007-2008$ & SIA & MOST & SIA & \\
\hline Haizheng I & 300 & 2010-2012 & CSSRC & CSSRC & CSSRC & \\
\hline Haishi/Haizheng II & 300 & 2011-2014 & CSSRC & SMU & SMU & \\
\hline Hadal & 11000 & 2013-2017 & SIA & CAS & IDSE & $\begin{array}{l}10767 \text { m (2016); } \\
10888 \text { m (2017) }\end{array}$ \\
\hline Rainbowfish & 11000 & 2013-2019 & SHOU & SHOU & RFOT & Sea trials reached $6300 \mathrm{~m}(2017)$ \\
\hline- & 11000 & $2016-2020$ & SJTU & MOST & NDSC & \\
\hline- & $11000 \mathrm{~m}$ & $2016-2020$ & SIA & MOST & IDSE & \\
\hline
\end{tabular}

restriction for the time limit of the bottom operation. In the "Rainbowfish" manned cabin, we propose one that is equipped with a toilet. The team is currently working on the interior design and additional tests.

In terms of the components manufactured for the development of an FOD HOV, the most critical components are the manned cabin, buoyancy material, battery, and high pressure pump/electronic DC motor. These parts are briefly discussed as follows.

For a manned cabin capable for three persons to work at FOD, a comparative study was carried out for several possible candidate materials (Cui et al. 2015); results demonstrated that only $1100 \mathrm{MPa}$ grade ultra-high strength titanium alloy or $1700 \mathrm{MPa}$ level of ultra-high strength steel is feasible.

Table 5 Gliders developed in China

\begin{tabular}{|c|c|c|c|c|c|c|}
\hline Name & Design depth/m & Development period & $\begin{array}{l}\text { Chief organization } \\
\text { for the development }\end{array}$ & Sponsor & User & Other important information \\
\hline Haiyi 300 & 300 & 2003-2009 & SIA & MOST & SIA & \\
\hline Haiyi1000 & 1000 & $2010-2014$ & SIA & MOST & SIA & \\
\hline Haiyi7000 & 7000 & $2015-2017$ & SIA & MOST & SIA & $\begin{array}{l}\text { Maximum sea trial depth } \\
6329 \mathrm{~m}(2017)\end{array}$ \\
\hline Haixiang & 500 & $2012-2016$ & CSSRC & SOA & CSSRC & Maximum sea trial depth 503 m (2016) \\
\hline Hai Yan & 1500 & 2009-2014 & TU & MOST & TU & Many products have been finished \\
\hline
\end{tabular}


Table 6 DTSs developed in China

\begin{tabular}{|c|c|c|c|c|c|}
\hline Name & Design depth/m & Development period & $\begin{array}{l}\text { Chief organization for } \\
\text { the development }\end{array}$ & Sponsor & User \\
\hline SJTU-ST6000 & 6000 & 1996-1999 & SJTU & COMRA & COMRA \\
\hline DTA 6000-I & 6000 & 2001-2014 & IOA & MOST & COMRA \\
\hline DTA 6000-II & 6000 & $2001-2015$ & IOA & MOST & COMRA \\
\hline
\end{tabular}

Table 7 Landers developed in China

\begin{tabular}{|c|c|c|c|c|c|}
\hline Name & Design depth/m & Development period & Chief organization for the development & Sponsor & User \\
\hline Cold sweep & 3000 & 2011-2013 & SIA & MOST & SIA \\
\hline Tianya & 11000 & 2013-2016 & SIA & CAS & IDSE \\
\hline Haijiao & 11000 & 2013-2016 & SIA & CAS & IDSE \\
\hline Rainbowfish I & 11000 & 2013-2016 & SHOU & SHOU & RFOT \\
\hline Rainbowfish II & 11000 & 2013-2016 & SHOU & SHOU & RFOT \\
\hline Rainbowfish III & 11000 & 2013-2016 & SHOU & SHOU & RFOT \\
\hline
\end{tabular}

However, for both materials, the welding performance is generally lower than that of the parent metal. To maximize ultra-high strength material properties, welding should be avoided as far as possible. By considering the maturity and economics for these two materials, ultra-high strength steel is chosen for "Rainbowfish" FOD HOV because both MIR I and MIR II used this material for more than 30 years, and their manned cabins remain in good condition (Wang et al. 2016a, b). Another FOD HOV was constructed with ultra-high strength titanium alloy (Lei et al. 2016a, b). Designing windows that fully satisfy the requirements of ASME PVHO ( 2007 is feasible. In MIR's experience, after a discussion with MIR's chief designer and MIR's pilot, three of us believe that the ASME rule is conservative. Thus, in the design of the manned cabin of "Rainbowfish," a new safety standard for windows is adopted; many tests need to be arranged to prove the validity of this new standard, and they are currently underway (Du et al. 2017).

In deep MSs, buoyancy is finely tuned through the use of a high pressure seawater pump. Buoyancy is adjusted by pumping sea water into or out of the tanks. The development of a reliable large-flow pump is quite challenging. Liu et al. (2014a, b) successfully developed a high pressure seawater pump for $4500 \mathrm{~m} \mathrm{HOV}$ "Shen Hai Yong Shi," and they are currently working on the $11000-\mathrm{m}$ HOV pump. In this variable ballast system, the design of a high-power oil-filled brushless DC motor is also a challenge (Hu et al. 2017).

The selection of a battery for MSs is another problem that needs to be considered. Previous MSs used lead acid, nickel cadmium, and silver zinc batteries; the current trend is the use of lithium ion batteries. In Shinkai 6500-m-deep MS, the lithium ion battery has been successfully used for many years (Ogura et al. 2004). In China, the lithium ion battery was successfully applied in "Shen Hai Yong Shi," and another project for the application of the lithium ion battery in FOD HOV was sponsored by MOST in 2016. We expect that battery technology will show rapid development in this decade, and powerful types of new batteries will occur in the near future.

The density of the buoyancy material exerts great effects on the total weight of the HOV. We have tested all the available buoyancy materials from international companies (Trelleborg Offshore Boston www.Trelleborg.com/AEM, Engineered

Table 8 Floats developed in China

\begin{tabular}{|c|c|c|c|c|c|}
\hline Name & Design depth/m & Development period & Chief organization for the development & Sponsor & User \\
\hline COPEX & 2000 & 1999-2003 & NOTC & MOST & NOTC \\
\hline HM2000 & 2000 & $2001-2005$ & 710 Institute & MOST & 710 Institute \\
\hline- & 4500 & 2016-2019 & OUC & NSFC & OUC \\
\hline- & 4500 & 2016-2019 & SJTU & NSFC & OUC \\
\hline Rainbowfish & 4500 & 2015-2018 & SHOU & RFOT & RFOT \\
\hline
\end{tabular}


Syntactic Systems www.esyntactic.com, Ron Allum Deepsea Services (RADS www.ronallum.com)) and two Chinese manufacturers, Marine Chemical Engineering Institute (Liang et al. 2016) and Technical Institute of Chemistry and Physics of the CAS (Wang et al. 2016a, b); all of them failed to satisfy the requirements of China classification society (Cui et al. 2018). Thus, a definition of its safe life will depend on the water absorption performance, and the selected buoyancy material needs to go through a complete test for its water absorption performance. Such work is underway via the Rainbowfish project.

Tables 1, 2, 3, 4, 5, 6, 7 and 8 provide a summary of all the submersibles developed in China, type by type. All the abbreviations used in tables are summarized here. Deep submergence rescue vehicle (DSRV), atmospheric diving suit (ADS), COPEX. Shanghai Jiao Tong University (SJTU), China Ship Scientific Research Center (CSSRC), Harbin Engineering University (HEU), Kuming Shipborne Equipment Research $\&$ Test Center (KSERTC), Ministry of Science and Technology of the People's Republic of China (MOST), National Deep Sea Center (NDSC), Institute of Deep-sea Science and Engineering (IDSE) of the CAS, China National Offshore Oil Corp. (CNOOC), Shanghai Ocean University (SHOU), Shanghai Rainbowfish Ocean Technology Co. Lt. (RFOT), Shenyang Institute of Automation (SIA) of the CAS, China Ocean Mineral Resources R\&D Association (COMRA), Guangzhou Marine Geological Survey bureau (GMGS), State Oceanic Administration (SOA), AutoSubsea Vehicles Inc. (AVI), Ministry of Industry and Information Technology of the People's Republic of China (MIIT), Shanghai Maritime University (SMU), Tianjin University (TU), Institute of Acoustics (IOA) of the CAS, National Ocean Technology Center (NOTC), No. 710 research institute (710 Institute) of China Shipbuilding Industry Cooperation (CSIC), Ocean University of China (OUC), and National Science Foundation of China (NSFC). This review demonstrates that Chinese deep sea technology has achieved great progress with the success of the Jiaolong deep MS. After this 5-year plan, they are capable of developing all FOD submersibles. China may become the first country in the world that owns an operational FOD HOV.

\section{Summary}

In this paper, the Chinese history of submersible research and development has been briefly reviewed. After a long period of hardship, China has already developed many practically used submersibles such as "Hailong II" of $3500 \mathrm{~m}$ and Hailong III of $6000 \mathrm{~m}$ ROV, "Haima" of $4500 \mathrm{~m}$ ROV, "Qianlong I" of $6000 \mathrm{~m}$ AUV, "Qianlong II" and "Qianlong III" of $4500 \mathrm{~m}$ AUV, "Jiaolong" of $7000 \mathrm{~m} \mathrm{HOV}$, and five FOD landers. Two
FOD unmanned submersibles and two FOD MSs are currently under development. Given these achievements, China can play a significant role in the investigation of the deepest oceans, namely, the hadal trenches $(6500-11000 \mathrm{~m})$.

Open Access This article is licensed under a Creative Commons Attribution 4.0 International License, which permits use, sharing, adaptation, distribution and reproduction in any medium or format, as long as you give appropriate credit to the original author(s) and the source, provide a link to the Creative Commons licence, and indicate if changes were made.

The images or other third party material in this article are included in the article's Creative Commons licence, unless indicated otherwise in a credit line to the material. If material is not included in the article's Creative Commons licence and your intended use is not permitted by statutory regulation or exceeds the permitted use, you will need to obtain permission directly from the copyright holder.

To view a copy of this licence, visit http://creativecommons.org/licenses/ by $/ 4.0 /$.

\section{References}

ASME PVHO-1 2007. Safety standard for pressure vessel for human occupancy. The American Society of Mechanical Engineers, Three Park Avenue, New York, NY 10016

Bowen AD, Yoerger DR, Whitcomb LL, Fornari DJ (2004) Exploring the deepest depths: preliminary design of a novel light-tethered hybrid ROV for global science in extreme environments. Mar Technol Soc J 38(2):92-101. https://doi.org/10.4031/002533204787522776

Cao JL, Cao JJ, Yao BH, Lian L (2015) Dynamics and adaptive fuzzy turning control of an underwater glider. MTS/IEEE 2015 - Genova: discovering sustainable ocean energy for a new world. https://doi. org/10.1109/OCEANS-Genova.2015.7271363

CENORF (2009) Science at sea: meeting future oceanographic goals with a robust academic research fleet, Committee on Evolution of the National Oceanographic Research Fleet (CENORF); National Research Council, the National Academies Press, Washington DC

Chen FY, Chen B, Guan JB, Jin WF (2015a) Glider collisions in hybrid cellular automaton rules. Complex Systems 24(3):185-221. https:// doi.org/10.25088/ComplexSystems.24.3.185

Chen YJ, Chen HX, Ma Z (2015b) Hydrodynamic analyses of typical underwater gliders. J Hydrodyn 27(4):556-561. https://doi.org/10. 1016/S1001-6058(15)60516-9

Chen ZE, Yu JC, Zhang AQ, Song SM (2015c) Control system for longrange survey hybrid-driven underwater glider. MTS/IEEE OCEANS 2015 - Genova: Discovering Sustainable Ocean Energy for a New World. https://doi.org/10.1109/OCEANS-Genova.2015. 7271706

Christ RD, Wernli RL (2014) ROV manual, 2nd edn. ButterworthHeinemann, Oxford

Cui WC (2013) Development of the Jiaolong deep manned submersible. Mar Technol Soc J 47(3):37-54. https://doi.org/10.4031/MTSJ.47. 3.2

Cui WC (2015) On the development strategy of a full ocean depth manned submersible and its current progress. Journal of Jiangsu University of Science and Technology (Natural Science Edition) 29(1):1-9. (in Chinese). https://doi.org/10.3969/j.issn.1673-4807. 2015.01.001 
Cui WC, Wu X (2018) A Chinese strategy to construct a comprehensive investigation system for hadal trenches. In TEAM2018, Oct.15-18, 2018, Wuhan, China

Cui WC, Liu F, Hu Z, Zhu M, Guo W, Liu CG (2013) On 7000m sea trials of the manned submersible "JIAOLONG". Mar Technol Soc J 47(1):67-82

Cui WC, Hu Y, Guo W, Pan BB, Wang F (2014) A preliminary design of a movable laboratory for hadal trenches. Methods in Oceanography 9:1-16. https://doi.org/10.1016/j.mio.2014.07.002

Cui WC, Wang F, Pan BB, Hu Y, Du QH (2015) Chapter 1 issues to be solved in the design, manufacture and maintenance of a full ocean depth manned cabin, in Advances in engineering research. Volume 11, Editors: Victoria M. Petrova, 2015 - 3rd Quarter, Nova Science Publishers

Cui WC, Hu Y, Guo W (2017) Chinese journey to the challenger deep: the development and first phase of sea trial of an 11,000-m rainbowfish ARV. Mar Technol Soc J 51(3):23-35

Cui WC, Guo J, Pan BB (2018) A preliminary study on the buoyancy materials for the use in full ocean depth manned submersibles. Journal of Ship Mechanics 22(6):736-757. https://doi.org/10.3969/ j.issn.1007-7294.2018.06.007

Cyranoski D (2016) What China's latest five-year plan means for science. Nature 531:524-525. https://doi.org/10.1038/nature.2016.19590

Deng CN, Ge T (2012) Model-free high order sliding controller for underwater vehicle with transient process. Adv Mater Res 591-593: 1184-1190. https://doi.org/10.4028/www.scientific.net/AMR.591593.1184

Deng ZG, Zhu DQ, Xu PF, Fang JN (2014) Hybrid underwater vehicle: ARV design and development. Sensors \& Transducers 164(2):278287

Du QH, Hu Y, Cui WC (2017) Safety assessment of the acrylic conical frustum viewport structure for a deep-sea manned submersible. Ships and Offshore Structures 12(S1):S221-S229. https://doi.org/ 10.1080/17445302.2016.1261390

Engineered Syntactic Systems. Technical data sheet for HZ grade microsphere syntactic foam. www.esyntactic.com

Fan SS, Woolsey C (2013) Elements of underwater glider performance and stability. Mar Technol Soc J 47(3):81-98. https://doi.org/10. 4031/MTSJ.47.3.4

Fan SB, Lian L, Ren P (2012) Research on hydrodynamics model test for deep sea open-framed remotely operated vehicle. China Ocean Engineering 26(2):329-339. https://doi.org/10.1007/s13344-0120025-1

Fan SS, Yang CJ, Peng SL, Li KH, Xie Y, Zhang SY (2014) Design and experimental research on key pressure subsystems of underwater glider. J Zhejiang Univ (Eng Sci) 48(4):633-640 (in Chinese). https://doi.org/10.3785/j.issn.1008-973X.2014.04.011

Fan XJ, Song DL, Su ZQ, Yang H, Liu XY, Sun WC (2016) Research and design of semi-physical motion simulation systemt of buoyancydriven underwater glider. OCEANS 2016 - Shanghai

Feng XS, Li YP, Xu HL (2011) The next generation of unmanned marine vehicles dedicated to the 50 anniversary of the human world record diving $10912 \mathrm{~m}$. Robot 33(1):113-118 (in Chinese). https://doi.org/ 10.3724/SP.J.1218.2011.00113

Gao X, Yu HJ, Ding K, Zhang Y, Zhao SY, Zhang TW (2016) Underwater navigation and calibration of Jiaolong manned submersible in the Southwest Indian Ridge hydrothermal vents. J Mar Sci Technol (Taiwan) 23(5):1041-1048. https://doi.org/10.6119/ JMST-016-0628-1

Gou P, Cui WC (2010) Application of collaborative optimization in the structural system design of underwater vehicles. Ships and Offshore Structures 5(2):115-123

Guo W, Wang XH, Zhu PQ, Liu KZ (2006) Multi-sensors data acquisition and information fusion for manned submersible vehicle. Chin $\mathrm{J}$ Sci Instrum 27(Suppl):1572-1574
Hu Y, Ren SH, Han H (2017) Design of oil-filled brushless DC motor for deep water propulsion. Northeast Electric Power Technology 38(7): 5-9 (in Chinese)

Jiang Z, Cui WC (2015) A review of the latest progress in research on hydrodynamic performance of full ocean depth submersibles. Shipbuilding of China 56(4):188-199 (in Chinese)

Kohnen W (2009) Human exploration of the deep seas: fifty years and the inspiration continues. Mar Technol Soc J 43(5):42-62. https://doi. org/10.4031/MTSJ.43.5.30

Lei JF, Ma YJ, Yang R, Wu SJ, Jiang L (2016a) Material and fabrication of the personnel hull for full ocean depth submersible. J Eng Stud 8(2):179-184 (in Chinese). https://doi.org/10.3724/SP.J.1224.2016. 00179

Lei Z, Wang YH, Zhang LH, Liu YH, Liu F (2016b) Uncertainty behavior research of hybrid underwater glider. OCEANS $2016-$ Shanghai. https://doi.org/10.1109/OCEANSAP.2016.7485407

Li S, Zeng JB, Wang YC (2011) Navigation under the arctic ice by autonomous \& remotely operated underwater vehicle. Robot 33(4):509-512 (in Chinese)

Li H, Li ZW, Cui WC (2013) A preliminary study of the resistance performance of the three manned submersibles with full ocean depth. Journal of Ship Mechanics 17(12):1411-1425. https://doi. org/10.3969/j.issn.1007-7294.2013.12.006

Lian L, Ma XF, Tao J (2015) Development process of 4500m class "Haima" system. Naval Architecture and Ocean Engineering 31(1):9-12 (in Chinese)

Liang XJ, Liang ZX, Zhou Y, Wang J, Wang QY, Chen X (2016) Properties of syntactic foams under full ocean depth. Thermosetting Resin 31(5):38-41 (in Chinese). https://doi.org/10. 13650/j.cnki.rgxsz.2016.05.009

Liu F, Wang YH, Niu WD, Ma ZS, Liu YH (2014a) Hydrodynamic performance analysis and experiments of a hybrid underwater glider with different layout of wings. OCEANS 2014 - TAIPEI

Liu YS, Wu DF, Li DL, Zhao XF (2014b) Seawater hydraulic buoyancy adjusting system for large-depth submersible. Chinese Hydraulics and Pneumatics, (10): 1-10 (in Chinese). https://doi.org/10.11832/j. issn.1000-4858.2014.10.001

Liu B, Liu KZ, Wang YY, Zhao Y, Cui SG, Wang XH (2015) A hybrid deep sea navigation system of LBL/DR integration based on UKF and PSO-SVM. Robot 37(5):614-620. https://doi.org/10.13973/j. cnki.robot.2015.0614

Lu SL, Sun CH, Liu ZH, Xu JP (2016) Comparative testing and data quality evaluation for COPEX, HM2000 and APEX profiling buoys. Ocean Technol 35(1):84-92 (in Chinese). https://doi.org/ 10.3969/j.issn.1003-2029.2016.01.014

Ma ZS, Wang YH, Wang SX, Yang YN (2016) Ocean thermal energy harvesting with phase change material for underwater glider. Appl Energy 178:557-566. https://doi.org/10.1016/j.apenergy.2016.06. 078

Marsset T, Marsset B, Ker S, Thomas Y, Le Gall Y (2010) High and very high resolution deep-towed seismic system: performance and examples from deepwater Geohazard studies. Deep-Sea Res I 57:628637. https://doi.org/10.1016/j.dsr.2010.01.001

McFarlane J (1990) ROV-AUV hybrid for operating to 38,000 feet. Mar Technol Soc J 24(2):87-90

Moorhouse PA (2015) Modern history of the manned submersible. Mar Technol Soc J 49(6):65-78

Nakajoh H, Murashima T, Aoki T, Tukioka S (1998) 7000m class expendable optical fibre cable ROV (UROV7K) system. In: Proceedings of the International Conference on Offshore Mechanics and Arctic Engineering-OMAE-98, July. pp. 5-9, Lisbon, Portugal, OMAE

Ogura S, Kawama I, Sakurai T, Yoshiume T, Lijima K,-Imai Y (2004) Development of oil filled pressure compensated lithium-ion secondary battery for DSV Shinkai 6500. Ocean '04-MTS/IEEE TechnoOcean '04: bridges across the oceans - conference proceedings 3 , 
1720-1726. Kobe, Tokyo. https://doi.org/10.1109/OCEANS.2004. 1406384

Pan BB, Cui WC (2012) Structural optimization for a spherical pressure hull of a deep manned submersible based on an appropriate design standard. IEEE J Ocean Eng 37(3):564-571. https://doi.org/10. 1109/JOE.2012.2190809

Pan BB, Cui WC (2014) On the development of reliability based multidisciplinary design optimization (RBMDO) approach for deep manned submersibles. Safety \& Reliability of Ships, Offshore \& Subsea Structures, August 18-20, Glasgow, UK

Pan BB, Cui WC (2017) Theory of multidisciplinary design optimization (MDO) and its application to the design of deep manned submersibles. Zhejiang Science and Technology Press

Pan BB, Cui WC, Shen YS, Liu T (2010) Further study on the ultimate strength analysis of spherical pressure hulls. Mar Struct 23(4):444 461. https://doi.org/10.1016/j.marstruc.2010.11.001

Pan BB, Cui WC, Shen YS (2012) Experimental verification of the new ultimate strength equation of spherical pressure hulls. Mar Struct 29(1):169-176. https://doi.org/10.1016/j.marstruc.2012.05.007

Pang Y, Zhang S, Xu Y (1999) Activities in underwater technology at Harbin Engineering University. Mar Technol Soc J 33(1):10-14. https://doi.org/10.4031/MTSJ.33.1.2

Ping W, Ma XF, Zhang JH, Huang YZ, Tang YT (2017) HAIMA ROV. Ship Sci Technol 39(8):138-145 (in Chinese.) https://doi.org/10. 3404/j.issn.1672-7649.2017.08.029

Qi ZF, Liu WX, Jia LJ, Qin YF, Sun XJ (2013) Dynamic modeling and motion simulation for wave glider. Appl Mech Mater 397-400:285290. https://doi.org/10.4028/www.scientific.net/AMM.397-400.285

Qian HB, Yu JC, Han P, Jiang WH, Li YH, Wang FF, Guo JJ (2016) Problems and countermeasures of the management of China's R \& D on large deep-sea submersible vehicles. High Technology Communication 26(2):200-206 (in Chinese)

Richardson PL, John HS (2001) Drifters and floats. In: Encyclopedia of ocean sciences. Academic Press, 767-774

Ron Allum Deepsea Services (RADS). Structural syntactic foam brochure. www.ronallum.com

Rudnick DL (2015) Ocean research enabled by underwater gliders. Annu Rev Mar Sci 2016(8):9.1-9.23. https://doi.org/10.1146/annurevmarine-122414-033913

Tao J, Chen ZH (2016) Development and application of HAIMA(ROV). Eur J Engl Stud 8(2):185-191 (in Chinese). https://doi.org/10.3724/ SP.J.1224.2016.00185

Teague J, Allen MJ, Scott TB (2018) The potential of low-cost ROV for use in deep-sea mineral, ore prospecting and monitoring. Ocean Eng 147:333-339. https://doi.org/10.1016/j.oceaneng.2017.10.046

Tenberg A, De Bovee F, Hall P, Berelson W, Chadwick D, Ciceri G, Crassous P, Devol A, Emerson S, Gage J, Glud R, Graziottini F, Gundersen J, Hammond D, Helder W, Hinga K, Holby O, Jahnke R, De Wilde P (1995) Benthic chamber and profiling landers in oceanography - a review of design, technical solutions and functioning. Prog Oceanogr 35:253-294. https://doi.org/10.1016/0079-6611(95) 00009-6

Tian WL, Song BW, Du XX, Mao ZY, Ding H (2012) Modeling and simulation of a novel autonomous underwater vehicle with glider and flapping-foil propulsion capabilities. China Ocean Engineering 26(4):603-622. https://doi.org/10.1007/s13344-012-0046-9

Trelleborg Offshore Boston, Inc. Trelleborg Eccofloat ${ }^{\circledR}$ syntactic foams, www.Trelleborg.com/AEM

Vedachalam N, Ramesh R, Bala Naga Jyothi V, Doss Prakash V, Ramadass GA (2018) Autonomous underwater vehicles - challenging developments and technological maturity towards strategic swarm robotics systems, Marine Georesources \& Geotechnology, Published online: 18 Apr 2018. https://doi.org/10.1080/1064119X. 2018.1453567

Wang F, Cui WC (2015) Experimental investigation on dwell-fatigue property of Ti-6Al-4V ELI used in deep-sea manned cabin. Mater
Sci Eng A 642(905):136-141. https://doi.org/10.1016/j.msea.2015. 06.089

Wang YH, Wang SX, Xie CG (2007) Dynamic analysis and system design on an underwater glider propelled by temperature difference energy. J Tianjin Univ Sci Technol 40(2):133-138 (in Chinese)

Wang YH, Zhang HW, Wang SX (2009) Trajectory control strategies for the underwater glider. 2009 International Conference on Measuring Technology and Mechatronics Automation, ICMTMA 2009, 918921. https://doi.org/10.1109/ICMTMA.2009.617

Wang B, Wu C, Ge T (2013a) Control system of a novel underwater vehicle for global ocean science to the deepest ocean. Proceedings of the 32nd Chinese Control Conference, CCC 2013, 7268-7272

Wang B, Wu C, Ge T (2013b) Self-repairing control system for a hybrid underwater vehicle. Adv Mater Res, 834/836: 1256-1262. https:// doi.org/10.4028/www.scientific.net/AMR.834-836.1256

Wang K, Wang F, Cui WC, Hayat T, Ahmad B (2014) Prediction of short fatigue crack growth of Ti-6Al-4V. Fatigue Fract Eng Mater Struct 37(10):1075-1086. https://doi.org/10.1111/ffe.12177

Wang F, Wang K, Cui WC (2015a) A simplified life estimation method for the spherical hull of deep manned submersibles. Mar Struct 44(1):159-170. https://doi.org/10.1016/j.marstruc.2015.09.003

Wang K, Wang F, Cui WC, Tian AL (2015b) Prediction of cold dwellfatigue crack growth of titanium alloys. Acta Metall Sin (English Lett) 28(5):619-627. https://doi.org/10.1007/s40195-015-0240-x

Wang F, Hu Y, Cui WC (2016a) Preliminary evaluation of maraging steels on its application to full ocean depth manned cabin. Journal of Ship Mechanics 20(12):1557-1572. https://doi.org/10.3969/j. issn.1007-7294.2016.12.006

Wang P, Yan KQ, Pan SL, Zhang JJ (2016b) Research development on solid buoyancy material for deep-sea application. Journal of Engineering Studies 8(2):223-229 (in Chinese)

Wang YH, Zhang YT, Zhang MM, Yang ZJ, Wu ZL (2017) Design and flight performance of hybrid underwater glider with controllable wings. Int J Adv Robot Syst 14(3):1-12. https://doi.org/10.1177/ 1729881417703566

Wu JG, Shi K, Liu J, Xu HX, Wang Y, Li Y, Xu CH (2014) Development and experimental research on the variable buoyancy system for the $6000 \mathrm{~m}$ rated class "Qianlong I" AUV. Journal of Ocean Technology 33(5):1-7 (in Chinese)

Wu ZL, Zhao MY, Wang YH, Liu YH, Zhang HW, Wang SX, Qi EM (2017) Path planning for underwater gliders with motion constraints. Lecture Notes in Electrical Engineering 408:3-10. https://doi.org/ 10.1007/978-981-10-2875-5_1

Wynn RB, Huvenne VAI, Le Bas TP, Murton BJ, Connelly DP, Bett BJ, Ruhl HA, Morris KJ, Peakall J, Parsons DR, Sumner EJ, Darby SE, Dorrell RM, Hunt JE (2014) Autonomous underwater vehicles (AUVs): their past, present and future contributions to the advancement of marine geoscience. Mar Geol 352:451-468. https://doi.org/ 10.1016/j.margeo.2014.03.012

Xu PF, Cui WC, Xie JY, Yue LN (2010) Control system design for autonomous and remotely-operated vehicle. Shipbuilding of China 51(4):100-109 (in Chinese)

Yang H, Ma J (2010) Nonlinear control for autonomous underwater glider motion based on inverse system method. Journal of Shanghai Jiaotong University (Science) 15(6):713-718. https://doi.org/10. 1007/s12204-010-1074-3

Yang CJ, Peng SL, Fan SS (2014) Performance and stability analysis for ZJU glider. Mar Technol Soc J 48(3):88-103. https://doi.org/10. 4031/MTSJ.48.3.6

Yu LZ (2003) The China's ocean profiling explorer- COPEX. Ocean Technol 22(3):47-55 (in Chinese)

Yu LZ, Zhang SY, Shang HM (2005) Progress of China ARGO float. Ocean Technol 24(2):121-129 (in Chinese)

Yu JC, Zhang AQ, Wang XH, Wu BJ (2007) Adaptive neural network control with control allocation for a manned submersible in deep 
sea. China Ocean Engineering 21(1):147-161. https://oi.org/10. 3321/j.issn:0890-5487.2007.01.013

Yu JC, Zhang AQ, Jin WM, Chen Q, Tian Y, Liu CJ (2011) Development and experiments of the sea-wing underwater glider. China Ocean Engineering 25(4):721-736. https://doi.org/10.1007/s13344-0110058-x

Zhang MJ, Chu ZZ (2011) Thruster fault detection, isolation and reconstruction for autonomous underwater vehicle. Journal of Nanjing University of Aeronautics and Astronautics 43(Suppl.1):142-146 (in Chinese)
Zhang L, Pang YJ, Li Y, Sun YS (2011) Motion control of AUV based on rudders and thrusters. Journal of Beijing University of Technology 37(1):40-46 (in Chinese)

Zhao M, Cui WC (2011) On the development of bi-level integrated system collaborative optimization. Struct Multidiscip Optim 43(1):7384

Zhao M, Cui WC, Li X (2015) Multidisciplinary design optimization of a human occupied vehicle based on bi-level integrated system collaborative optimization. China Ocean Engineering 29(4):599-610. https://doi.org/10.1007/s13344-015-0042-y

Zhu JM (2001) Deep ocean research activity in China. Proceedings of the International Offshore and Polar Engineering Conference, 668-673 